\title{
CARACTERÍSTICAS EVIDENCIÁVEIS DE ESTRESSE EM DISCENTES DE ENFERMAGEM
}

\author{
Paulo Celso Prado Telles Filho* \\ Elaine Pires* \\ Giovana Abrahão Araújo*
}

\section{INTRODUÇÃO}

A despeito dos benefícios advindos da ciência e tecnologia, tanto a qualidade de vida como a sobrevivência humana vêm sendo ameaçadas por vários fatores, os quais contribuem para o agravamento de respostas adaptativas do indivíduo ao contexto sóciocultural e às suas rápidas e profundas mudanças. Essas respostas adaptativas têm tido repercussão imediata na saúde individual e coletiva, contribuindo para o surgimento de danos, como por exemplo, o estresse crônico e a dor crônica (SANTOS, 1989).

Define-se estresse como a força física ou psicológica que, quando aplicada a um sistema, é suficiente para provocar tensões ou distorções, ou quando muito grande, alterações no sistema. Os indivíduos experimentam estresse quando defrontamse com situações de vida que exigem a tomada de providência para resolver algum problema ou crise (IRVING, 1979).

O estresse tem sido evidenciado em significativa parcela da população e bastante comentado entre vários discentes do último semestre do curso de graduação da Escola de Enfermagem de Ribeirão Preto-Universidade de São Paulo.

Este estudo trata, especificamente, do estresse em discentes do último período de graduação em enfermagem, que em vista do momento de mudanças e indecisões, frente às diversas possibilidades profissionais, costumam apresentar características com ele condizentes. Verificou-se, portanto, a necessidade da realização de um estudo objetivando a detecção e quantificação de características evidenciáveis de estresse na referida população.

\section{OBJETIVO}

Este estudo objetiva a caracterização da população estudada, bem como a detecção e verificação de intensidade de características evidenciáveis de estresse nos discentes regularmente matriculados no $8^{\circ}$ semestre do Curso de Graduação de uma instituição de ensino superior em enfermagem.

\section{METODOLOGIA}

\subsection{Cenário de estudo}

Esta pesquisa foi realizada em instituição de ensino superior em enfermagem, na cidade de Ribeirão Preto, interior do Estado de São Paulo.

\subsection{Amostra e população de estudo}

A amostra consta dos 75 discentes regularmente matriculados no $8^{\circ}$ semestre do curso de graduação da citada instituição. Conseguiu-se localizar 66 discentes, o equivalente a $88 \%$ do total. Destes obteve-se o retorno de 46 instrumentos $(61,3 \%)$. Assim a população do presente estudo constituiu-se de 46 discentes.

\subsection{Instrumento de coleta de dados}

Elaborou-se um instrumento de coleta de dados, contendo questões abertas e fechadas, abordando dados sobre caracterização pessoal e características evidenciáveis de estresse.

* Discentes do $8^{\circ}$ semestre do Curso de Graduação da Escola de Enfermagem de Ribeirão Preto da Universidade de São Paulo 


\subsection{Tratamento estatístico}

Os dados foram analisados através de números absolutos e percentuais.

\section{RESULTADOS}

\subsection{Caracterização da população estudada}

O perfil da população estudada assim se apresenta: 45 indivíduos (ou 97,8\%) da população são do sexo feminino, a faixa etária varia de 21 a 46 anos, sendo a idade de 22 anos a que mais aparece (com 17 indivíduos, ou 37,0\%), 42 indivíduos (ou 91,3\%) são solteiros, 3 (ou $6,5 \%$ ) casados e 1 ( ou $2,1 \%$ ) desquitado, 11 indivíduos, o que eqüivale a $23,9 \%$ da população estudada, pratica atividade física, 18 indivíduos ou
$39,1 \%$ participam de atividades não relacionadas à grade curricular da graduação, tais como bolsa de iniciação científica (contando com 12 indivíduos ou 26,1\%) e curso de inglês com 11 indivíduos (ou 23,9\%), 44 indivíduos, ou 95,6\% dos participantes do estudo não fazem seguimento psicológico e 18 (ou 39,1\%) residem com a família. As expectativas mais citadas para o futuro fazem referência a emprego, trabalho, remuneração salarial, vínculo empregatício urgente e realização profissional.

\subsection{Apresentação das características evidenciáveis de estresse}

Os dados obtidos apresentam-se em forma de tabela, para melhor visualização das características registradas.

Quadro 1 - Intensidade das características evidenciáveis de estresse em números absolutos e em porcentagem

\begin{tabular}{|c|c|c|c|c|c|c|}
\hline $\begin{array}{ll}\text { Características } & \text { Intensidade } \\
\end{array}$ & 0* & $1 *$ & $2 *$ & 3* & $4 *$ & Total \\
\hline Respiração ofegante & $19-41,3 \%$ & $20-43,5 \%$ & $6-13,0 \%$ & - & $1-2,2 \%$ & $46-100 \%$ \\
\hline Taquicardia & $11-23,9 \%$ & $21-45,7 \%$ & $11-23,9 \%$ & $3-6,5 \%$ & - & $46-100 \%$ \\
\hline Desgaste ao final do dia & $3-6,5 \%$ & $7-15,2 \%$ & $17-37,0 \%$ & $18-39,1 \%$ & $1-2,2 \%$ & $46-100 \%$ \\
\hline Falta de apetite & $14-30,4 \%$ & $17-37,0 \%$ & $6-13,0 \%$ & $9-19,6 \%$ & - & $46-100 \%$ \\
\hline Excesso de apetite & $17-37,0 \%$ & $18-39,1 \%$ & $4-8,7 \%$ & $7-15,2 \%$ & - & $46-100 \%$ \\
\hline Roer unhas & $22-47,8 \%$ & $9-19,6 \%$ & $5-10,9 \%$ & $10-21,7 \%$ & - & $46-100 \%$ \\
\hline Pensamentos que provocam ansiedade & $4-8,7 \%$ & $9-19,6 \%$ & $15-32,6 \%$ & $16-34,8 \%$ & $2-4,3 \%$ & $46-100 \%$ \\
\hline Medo & $9-19,6 \%$ & $19-41,3 \%$ & $14-30,4 \%$ & $4-8,7 \%$ & - & $46-100 \%$ \\
\hline Desânimo e/ou cansaço & $1-2,2 \%$ & $16-34,8 \%$ & $16-34,8 \%$ & $13-28,3 \%$ & - & $46-100 \%$ \\
\hline Esgotamento emocional & $6-13,0 \%$ & $17-37,0 \%$ & $9-19,6 \%$ & $14-30,4 \%$ & - & $46-100 \%$ \\
\hline Angústia & $4-8,7 \%$ & $25-54,3 \%$ & $7-15,2 \%$ & $10-21,7 \%$ & - & $46-100 \%$ \\
\hline Distúrbios gastrointestinais & $15-32,6 \%$ & $19-41,3 \%$ & $6-13,0 \%$ & $6-13,0 \%$ & - & $46-100 \%$ \\
\hline Faltas das aulas ou estágios & $16-34,8 \%$ & $18-39,1 \%$ & $7-15,2 \%$ & $5-10,9 \%$ & - & $46-100 \%$ \\
\hline Insônia & $17-37,0 \%$ & $16-34,8 \%$ & $8-17,4 \%$ & $5-10,9 \%$ & - & $46-100 \%$ \\
\hline Irritação & $3-6,5 \%$ & $18-39,1 \%$ & $16-34,8 \%$ & $8-17,4 \%$ & $1-2,2 \%$ & $46-100 \%$ \\
\hline Náuseas & $28-60,9 \%$ & $12-26,1 \%$ & $2-4,3 \%$ & $3-6,5 \%$ & $1-2,2 \%$ & $46-100 \%$ \\
\hline Apatia & $18-39,1 \%$ & $20-43,5 \%$ & $2-4,3 \%$ & $4-8,7 \%$ & $2-4,3 \%$ & $46-100 \%$ \\
\hline Fumo excessivo & $36-78,3 \%$ & $3-6,5 \%$ & $2-4,3 \%$ & $5-10,9 \%$ & - & $46-100 \%$ \\
\hline Depressão & $16-34,8 \%$ & $21-45,7 \%$ & $7-15,2 \%$ & $1-2,2 \%$ & $1-2,2 \%$ & $46-100 \%$ \\
\hline Esquecimento & $7-15,2 \%$ & $21-45,7 \%$ & $9-19,6 \%$ & $6-13,0 \%$ & $3-6,5 \%$ & $46-100 \%$ \\
\hline Sono exagerado & $7-15,2 \%$ & $24-52,2 \%$ & $11-23,9 \%$ & $4-8,7 \%$ & - & $46-100 \%$ \\
\hline Cefaléia & $12-26,1 \%$ & $18-39,1 \%$ & $9-19,6 \%$ & $7-15,2 \%$ & - & $46-100 \%$ \\
\hline Pesadelos & $23-50,0 \%$ & $16-34,8 \%$ & $2-4,3 \%$ & $5-10,9 \%$ & - & $46-100 \%$ \\
\hline Vontade de abandonar o que está fazendo & $18-39,1 \%$ & $16-34,8 \%$ & $8-17,4 \%$ & $4-8,7 \%$ & - & $46-100 \%$ \\
\hline Discussão com amigos e familiares & $11-23,9 \%$ & $20-43,5 \%$ & $11-23,9 \%$ & $4-8,7 \%$ & - & $46-100 \%$ \\
\hline Vontade de ficar só & $3-6,5 \%$ & $22-47,8 \%$ & $7-15,2 \%$ & $14-30,4 \%$ & - & $46-100 \%$ \\
\hline
\end{tabular}




\section{CONSIDERAÇÕES FINAIS}

Este estudo detectou a existência de várias características evidenciáveis de estresse na população estudada, algumas em maior, outras em menor intensidade.

Dentre as várias informações obtidas através do quadro acima, vale comentar as que destacaram-se nos diversos níveis de intensidade apresentados: no nível de intensidade poucas vezes, sobressaiu a angústia com 25 (54,3\% da população estudada), taquicardia com 21 (45,7\%), respiração ofegante com 20 indivíduos $(43,5 \%)$ e distúrbios gastrointestinais com 19 (41,3\%), no nível freqüentemente, os que se destacaram foram irritação, desanimo e/ou cansaço com 16 indivíduos $(34,8 \%)$ e discussão com amigos e familiares contando com 20

\section{REFERÊNCIAS BIBLIOGRÁFICAS}

01. IRVING, S. Enfermagem psiquiátrica básica.

Trad. de Fernando Diniz Mundim, Maria Dolores Lins de Andrade. 2. ed. Rio de Janeiro: Interamericana, 1979. indivíduos (43,5\%). No nível sempre, 18 indivíduos $(39,1 \%)$ responderam sentir desgaste ao final do dia, $16(34,8 \%)$ apresentam pensamentos que provocam ansiedade e $14(30,4 \%)$ apresentam esgotamento emocional. Em contrapartida itens relacionados ao nível nunca também destacaram-se: fumo excessivo com 36 indivíduos $(78,3 \%)$, náuseas com $28(60,9 \%)$ e pesadelos com $23(50,0 \%)$.

O estudo revela, ainda, a caracterização da população estudada, ou seja: a maioria dos indivíduos são do sexo feminino, em idade de 22 anos, solteiros e não praticam atividade física ou atividades não ligadas à graduação.

Faz-se necessário a elaboração de trabalhos futuros para a avaliação dos fatores desencadeantes destes dados e mesmo para sua minimização.

02. SANTOS, V. Proposta alternativa de ensinoaprendizagem para o auto-cuidado, uma contribuição de enfermagem ao enfrentamento da dor e equalização do estresse. Ribeirão Preto, 1989. Tese (Doutorado) - Escola de Enfermagem de Ribeirão Preto, Universidade de São Paulo. 